\title{
Complexing properties of the $\beta$ metallothionein domain with cadmium and/or zinc, studied by differential pulse polarography
}

\author{
M. Dabrio and A.R. Rodríguez* \\ European Commission, Joint Research Centre, Institute for Reference Materials and Measurements, Retieseweg, B-2440 Geel, Belgium
}

\begin{abstract}
An electrochemical study of the complexing properties of the $\beta$ metallothionein domain with cadmium and/or zinc was performed at $\mathrm{pH} 8$, using differential pulse polarography. The applied technique allows one to obtain well-defined peaks corresponding to the free metal ions as well as providing evidence that different forms of complexation of $\mathrm{Cd}$ (II) and $\mathrm{Zn}$ (II) with the $\beta$ domain exist. The influence of sequential additions of $\mathrm{Cd}$ and/or $\mathrm{Zn}$ to the $\beta$ domain was investigated. The $\beta$ domain is capable of complexing cadmium and/or zinc, separately or after simultaneous additions, resulting in complexes with a of $M: \beta$ ratio of $3: 1$, but which possess different characteristics. In the case of binary mixtures, $\mathbf{C d}+\beta$ or $\mathbf{Z n}+\beta$, pure complexes with a probable stoichiometry of $\mathrm{Cd}_{3} \beta$ and $\mathrm{Zn}_{3} \beta$ are formed, whereas in the case of tertiary mixtures, $\beta+[\mathrm{Cd}+\mathrm{Zn}]$ mixed cadmium and zinc complexes $\mathrm{Cd}_{2} \mathrm{Zn} \beta$ and $\mathrm{CdZn}_{2} \beta$ prevail. When one of the two metal ions is added to a solution containing the $\beta$ domain complex with the other cation, it is incorporated into the molecule resulting in a reorganisation, which is illustrated by changes in the polarographic responses.

Polarographic results have been compared with those obtained by electrospray ionisation mass spectrometry, providing the molecular mass of compounds under similar experimental conditions. Different polarographic peaks are found for either pure or mixed complexes.
\end{abstract}

cysteines participate in metal binding. While in the case of MT, their structure and characteristics have been studied using a great variety of analytical methods [1-7], relatively few studies have been performed with the $\alpha$ and $\beta$ clusters separately probably due to the difficulties associated with their obtention. In fact these two domains are usually obtained by synthesis using either solid-phase and fragmentcondensation techniques or isolated by proteolysis of metallothioneins of different origin. Nevertheless the use of chemically synthesised and well-characterised separate $\alpha$ and $\beta$ domains could be very interesting for the study of their metal binding properties and therefore contribute to the understanding of the behaviour of the entire MT.

The aim of this research is the systematic study of the complexing properties of the $\beta$ MT domain with cadmium and/or zinc using electroanalytical methods. These methods have been widely used by our team for the investigation of MT [8-16] and related molecules such as the peptidic fragment Lys-Cys-Thr-Cys-Ala (56-61) MT-1 (FT) alone and in the presence of cadmium and/or zinc [17-25]. In the case of MT and related molecules, the aminoacid chain is electroactive due to the presence of thiol groups. Moreover, the reduction of the cations, cadmium and zinc, is electrochemically reversible at the mercury electrode and, hence it is possible to obtain three different responses simultaneously for the sample under a given set of experimental conditions. In addition, the electrochemical response depends on the chemical form of the element and allows one to monitor the changes of the different species in solution as a function of different parameters.

The $\beta$ domain has been isolated using different methods $[3,7]$ and its binding properties have been investigated using mainly spectroscopic methods [3,7,26-33]. The synthesised peptide used in this work has been purchased from the Biochemistry Institute of Zurich University. The purity of this molecule was checked by both Dr. Klauser's team from Zurich University and our team using electrospray ionisation mass spectrometry (ESI-MS) [34,35].

The binding properties have been studied, using differential pulse polarography, with different types of additions of metal ions to the apo- $\beta$ domain and the inverted addition of the $\beta$ MT domain to metal ions, the gradual addition of metal ions separately and the addition of both cations simultaneously. The use of the apo- $\beta$ MT domain has the

* Correspondence and reprints 
advantage over the $\mathrm{Cd}$, ZnMT in that it permits one to study the behaviour of the cadmium and zinc thiolate complexes separately which is not possible with the MT, as well as the influence of one metal ion on the complexing properties of the other. Likewise, the influence of the $\mathrm{pH}$ in a narrow range was also investigated.

The polarographic results are compared with those obtained recently by our team [35] using ESI-MS under similar experimental conditions.

\section{Experimental}

\section{Apparatus}

All measurements were performed using a potentiostat BAS Model 100B/W electrochemical analyser, connected to a BAS Controlled Growth Mercury Electrode polarographic stand equipped with a HDME as the working electrode, a $\mathrm{Ag} / \mathrm{AgCl}$ reference electrode and a platinum wire as an auxiliary electrode. This equipment was introduced into a glove box, Plas Labs, Inc. 830-ABC Series Chambers, connected to a diaphragm pump Vacuubrand Gmbh+Co model ME-4, so as to avoid oxidation of the MT thiol groups by the $\mathrm{O}_{2}$ present in the air during sample manipulation. The purge gas used was $99.999 \% \mathrm{~N}_{2}$.

A pH meter, Orion Model 920A, equipped with a glass electrode combined with an $\mathrm{Ag} / \mathrm{AgCl}$ reference electrode, was employed for the $\mathrm{pH}$ measurements.

\section{Chemicals}

$\beta$ domain sample, whose aminoacid sequence corresponds to a human MT, was synthesised and purified by the Biochemistry Institute of Zurich University, by peptide synthesis, following the procedure described in a personal communication [34].

\section{HuMT-beta (31 residues, N-terminal Met acetylated)}

Ac-Met-Asp-Pro-Asn-Cys-Ser-Cys-Ala-Ala-Gly-Asp-SerCys-Thr-Cys-Ala-Gly-Ser-Cys-Lys-Cys-Lys-Glu-Cys-LysCys-Thr-Ser-Cys-Lys-Lys-OH.

No impurities or metal cations were detected. $\beta$ domain was provided in powder form, and stored at $-30{ }^{\circ} \mathrm{C}$ without any further purification. Samples were freshly prepared before measurement under an inert atmosphere.

The supporting electrolyte was prepared from equimolar amounts of phosphoric acid and 2-[4-(2-hidroxyethyl)-1piperazinyl] ethanesulphonic acid (HEPES) and was used as a buffer, adjusting the $\mathrm{pH} 8$ by addition of $\mathrm{NaOH}$.

Cadmium and zinc solutions used in the study of metal additions were prepared from Titrisol Standard solutions of 1000 mg.L L $^{-1}$ purchased from Merck.
All solutions were prepared using pure water obtained from an ultra-pure water system, MilliQ plus Model 185 (Millipore SA, Molsheim, France), and deoxygenated before use, by purging with $\mathrm{N}_{2}$. All the reagents employed were of analytical grade.

Hexadistilled mercury, grade $9 \mathrm{~N}$, for use in the polarographic mercury reservoir was purchased from Rhône-Alpes Mercure. Purging was carried out with $99.999 \% \mathrm{~N}_{2}$.

\section{Electrochemical procedure}

The supporting electrolyte was purged with nitrogen for 10 minutes before the start of the experiments. The samples were purged continuously between each measurement and during the experiment nitrogen was passed over the cell. All of the studies were carried out in an inert atmosphere inside a glove box at room temperature.

Each sample was measured by DPP over a large cathodic scan range of potentials, from $-200 \mathrm{mV}$ to $-1350 \mathrm{mV}$, with the aim of obtaining good development of the voltammetric peaks.

Experimental parameters used had been optimised in previous works [20]. In all cases, the drop size is the same and depends on the number of pulses $(n p=5)$ and the pulse width $(\mathrm{pw}=10 \mathrm{msec})$. Differential Pulse Polarography (DPP) was carried out using a scan rate of $4 \mathrm{mV}^{\mathrm{s}} \mathrm{s}^{-1}$ with a drop time of $1 \mathrm{~s}$ and the pulse amplitude fixed at $10 \mathrm{mV}$.

The aim of this experiment is to monitor the evolution of a solution containing either the $\beta$ domain or one of the metal ions selected for this work, $\mathrm{Cd}$ or $\mathrm{Zn}$, when gradual additions of the rest of the components are performed following a pre-established order. The experiments programmed are:

- Addition of $\mathrm{Cd}$ to the $\beta$ domain and subsequent addition of $\mathrm{Zn}$.

- Addition of $\mathrm{Zn}$ to the $\beta$ domain and subsequent addition of $\mathrm{Cd}$.

- Addition of the $\beta$ domain to $\mathrm{Cd}$ and subsequent addition of $\mathrm{Zn}$.

- Addition of the $\beta$ domain to $\mathrm{Zn}$ and subsequent addition of $\mathrm{Cd}$.

- Addition of an equimolar solution of $\mathrm{Cd}$ and $\mathrm{Zn}$ to the $\beta$ domain.

- Addition of the $\beta$ domain to an equimolar solution of $\mathrm{Cd}$ and $\mathrm{Zn}$.

\section{Results and discussion}

\section{Polarographic behaviour of the $\beta$ MT domain during sequential additions of cadmium or zinc separately}

Firstly, standard additions of metal ions, cadmium and zinc, to a solution containing the $\beta$ domain and, secondly, additions of the $\beta$ domain to separate solutions containing $\mathrm{Cd}$ or $\mathrm{Zn}$ have been carried out. The experiments have been 
performed under the same experimental conditions at $\mathrm{pH} 8$. This $\mathrm{pH}$ has been chosen because the complete formation of Cd- $\beta$ and $\mathrm{Zn}-\beta$ complexes can be reached. In the case of standard additions of cadmium to the $\beta$ domain, it is possible to clearly distinguish the signal corresponding to free $\mathrm{Cd}^{2+}$ and complexed cadmium (see Fig. 1) because both peaks are nicely resolved and, therefore the additions of cadmium were carried out until an excess of $\mathrm{Cd}^{2+}$ was detected. In the case of zinc additions it is not possible to clearly distinguish between the peak attributed to the complexed zinc and the one of free zinc because both potentials are very close to each other and, in this case, the addition of zinc was carried out until it was considered that the polarogram's features did not exhibit significant changes. In order to improve the distinction between different peaks, particularly of those corresponding to the reduction of $\mathrm{Zn}$ (II) all peaks have been resolved using a special software. Throughout this paper all results of peak potentials and peak current are those obtained applying this calculation programme, PeakFit v.4.1 for Windows Jandel Scientific Software.

An example of various polarogrammes obtained for cadmium (A) or zinc (B) gradual additions is shown in figure 1, in which the potentials corresponding to free cations, in the same medium, are indicated by vertical lines. In this figure all peaks which could be found in binary mixtures are presented. The polarographic peaks have been assigned in accordance with former studies on Cd, ZnMT [8-16] and on the cadmium and zinc complexed with FT using DPP $[18,19,21-23]$. Peaks labelled $\beta(\mathrm{Cd})$ and $\beta(\mathrm{Zn})$ have been attributed to the oxidation of the mercury electrode in the presence of thiol groups complexed by cadmium and zinc, respectively. Peaks labelled $\mathrm{Cd} \beta, \mathrm{Zn} \beta$ ' and $\mathrm{Zn} \beta$ are due to the reduction of metal ions complexed by the peptide. The electrochemical reactions are described elsewhere $[9,14]$.

When metal ions are added (Fig. 1) the formation of complexes with the $\beta$ domain occurs which is demonstrated by the growth in intensity of oxidation peaks, $\beta(\mathrm{Cd})$ and $\beta(\mathrm{Zn})$ and reduction peaks, $\mathrm{Cd} \beta, \mathrm{Zn} \beta$ ' and $\mathrm{Zn} \beta$.

When the inverted additions are performed, that is to say the gradual addition of the $\beta$ domain to separate solutions of $\mathrm{Cd}$ and $\mathrm{Zn}$, the analogous evolution of polarographic peaks is observed. When the $\beta$ domain is solely present in the supporting electrolyte, the peak named $\beta$ is only observed in some cases using DPP; however if square wave voltammetry is used, this $\beta$ peak is very well defined and detected at $-709 \mathrm{mV}$ (results not shown). This peak is attributed to the oxidation of the mercury electrode in the presence of free thiol groups and due to an adsorption process [14,20-24].

All peaks have been resolved as previously mentioned. The application of a mathematical program to the resolution of $\mathrm{Zn}$ (II) peaks is not an ideal solution, but it is the only one at present. It is necessary to note that the $\mathrm{Zn} \beta$ ' and $\mathrm{Zn} \beta$ peak potential are fixed by the program in order to obtain the best resolution, but these values could be different from one experiment to another $(\sim 30 \mathrm{mV})$ and therefore the evolution of $\mathrm{Zn}(\mathrm{II})$ complexes is not very decisive.

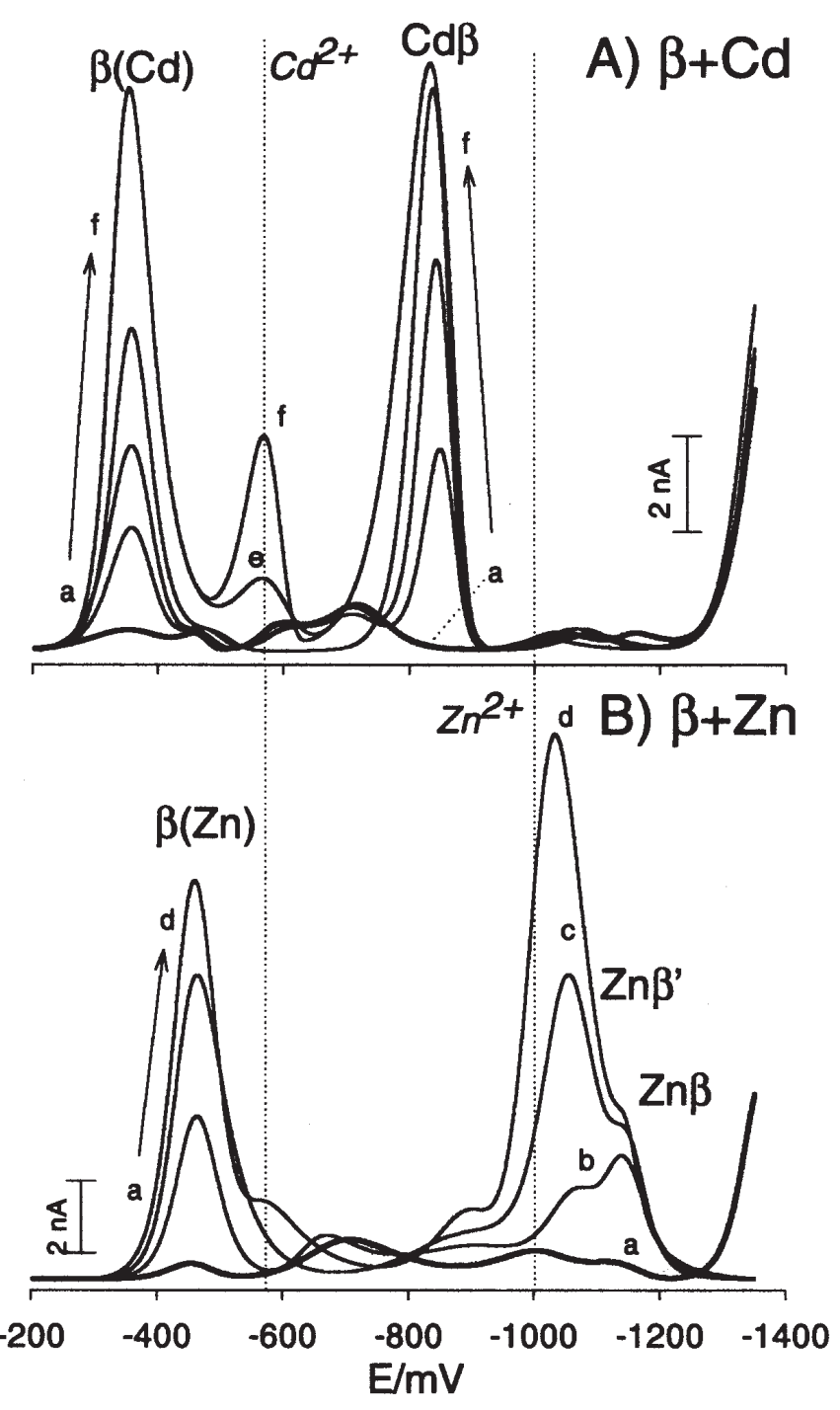

Figure 1. DPP polarograms corresponding to the sequential addition of $\mathrm{Cd}$ or $\mathrm{Zn}(\mathrm{mol} / \mathrm{mol} \beta)$ to a $\beta-\mathrm{MT} 5.5 \times 10^{-6} \mathrm{M}$ in HEPES-phosphate buffer $10^{-2} \mathrm{M}$ at $\mathrm{pH}$ 8.0. A) Additions of $\mathrm{Cd}$ : a) 0.0 ; b) 0.4 ; c) 0.9 ; d) 1.4 ; e) 2.7 ; f) 3.2 ; and B) Additions of $\mathrm{Zn}$ a) 0.0 ; b) 0.9 ; c) 1.8 ; d) 3.2 .

To compare the evolution of species during additions of metal ions to the $\beta$ domain and the inverted additions, the peak current of polarographic peaks as a function of the added compound $(\mathrm{mol} / \mathrm{mol})$ are represented in figure 2 . The $\beta(\mathrm{Cd})$ and $\operatorname{Cd} \beta$ peak currents increase with different slopes $\left(\rho_{\beta(C d)}\right) \approx 1 / 2\left(\rho_{\mathrm{Cd} \beta}\right), \mathrm{Ip}_{\mathrm{Cd} \beta}$ reaches a maximum for $[\mathrm{Cd}]_{\mathrm{ad}}>1.5$. A similar and constant value for both intensities is obtained for $[\mathrm{Cd}]_{\mathrm{ad}}>2.7$, which coincides with the detection of free $\mathrm{Cd}^{2+}$ indicating that the saturation of the $\beta$ domain is reached at a proportion of $[\beta]:[\mathrm{Cd}] \approx 1: 3$ (Fig. $2 \mathrm{a}$ ).

The variation of peak current when zinc is added is more complicated than in the case of added cadmium because of 


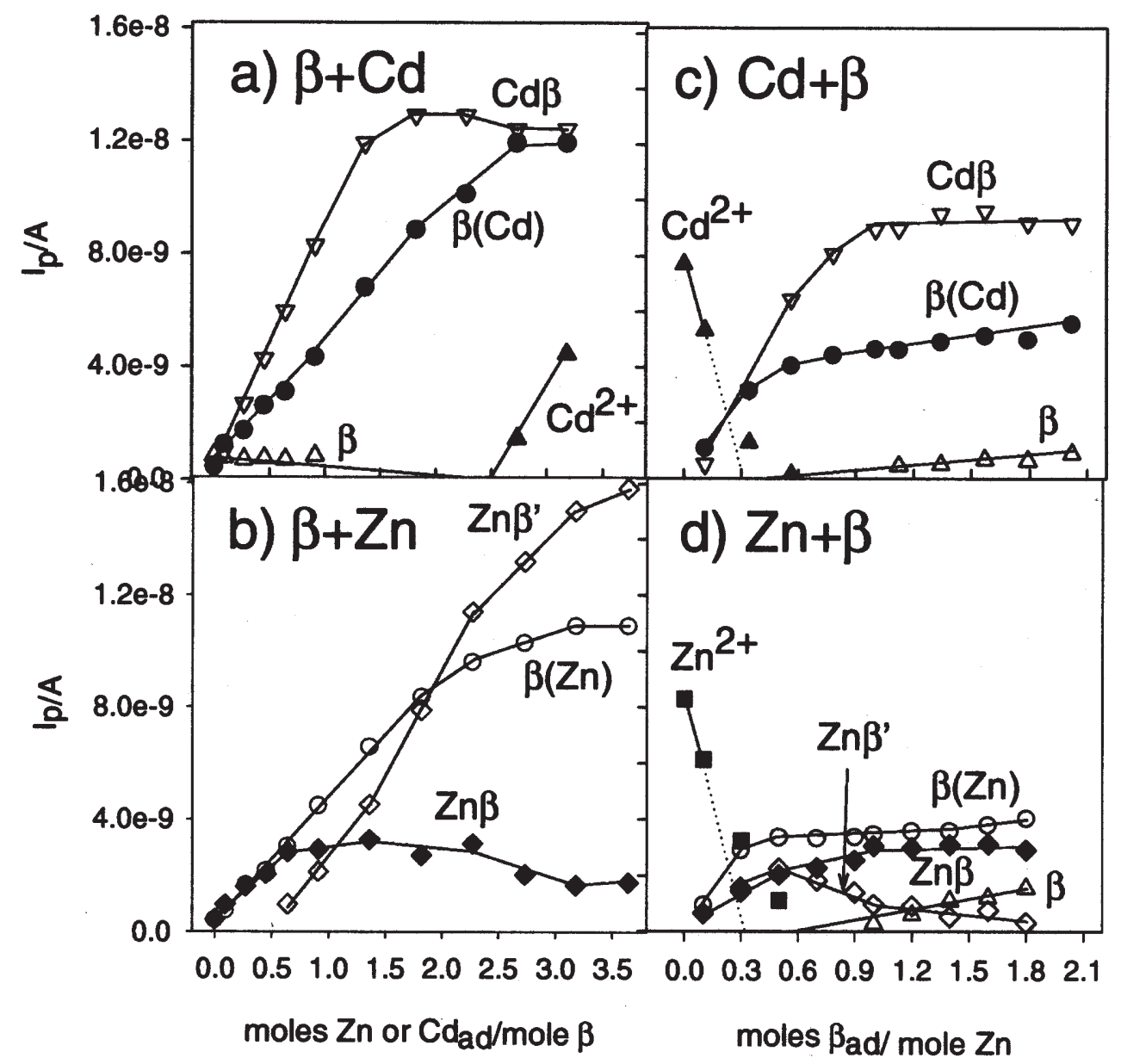

Figure 2. Peak current evolution vs. the amount of $\mathrm{Cd}(\mathrm{a})$ or $\mathrm{Zn}(\mathrm{b})$ added to a $\beta$-MT $5.5 \times 10^{-6} M$ in HEPES-phosphate buffer $10^{-2} \mathrm{M}$ at $\mathrm{pH} 8.0$; and vs. the amount of $\beta$ added to both solutions $5 \times 10^{-6} \mathrm{M}$ of $\mathrm{Cd}$ (c) and $\mathrm{Zn}$ (d) in the same medium.

the detection of two peaks attributed to two different complexation forms of zinc with the $\beta$ domain. As previously described, the $\beta(\mathrm{Zn})$ peak current increases until reaching an unchanged value at $[\mathrm{Zn}]_{\mathrm{ad}} \approx 3 \mathrm{Zn} / \mathrm{mol} \beta$. The first detected signal due to the $\mathrm{Zn}$ (II) reduction corresponds to the $\mathrm{Zn} \beta$ peak, its intensity increases with the same slope as the $\beta(\mathrm{Zn})$ peak until $[\mathrm{Zn}]_{\mathrm{ad}} \approx 0.5 \quad(\beta: \mathrm{Zn} \approx 2: 1)$ and then remains unchanged. At the same proportion the $\mathrm{Zn} \beta$ ' peak appears and its current increases with a similar slope to the one of the $\beta(\mathrm{Zn})$ peak and reaches a plateau. All intensities remain almost constant at a proportion of $\beta: \mathrm{Zn} \approx 1: 3$ and higher, indicating the total complexation of the initial $\beta$ (Fig. 2b).

The inverted additions of $\beta$ to cadmium or zinc was performed so as to obtain a great excess of $\beta$ in solution (Fig. 2c and d) or only a slight excess of $\beta,[\beta]=1 / 3[\mathrm{M}]$ (see Fig. 7). The variation of peak current when $\beta$ is added shows that $\mathrm{Cd}^{2+}$ peak (Fig. 2c) and $\mathrm{Zn}^{2+}$ (Fig. 2d) disappear at a proportion $[\beta]_{\mathrm{ad}} \approx 0.3 \mathrm{~mol} / \mathrm{mol} \mathrm{M}$, i.e. at $\beta: \mathrm{Cd}$ and $\beta: \mathrm{Zn} \approx 1: 3 . \beta(\mathrm{Cd})$ and $\beta(\mathrm{Zn})$ peak currents reach a constant value at the same proportion of added $\beta$. The $\operatorname{Cd} \beta$ peak intensity increases up to $\beta \approx 0.7$, indicating a proportion of $\beta: \mathrm{Cd} \approx 1: 1.5$ with a $\mathrm{Ip}_{\mathrm{Cd} \beta} \approx 2 \mathrm{Ip}_{\beta(\mathrm{Cd})}$. In the case of $\mathrm{Zn}$ complexes the $\mathrm{Zn} \beta$ ' signal increases until $[\beta]_{\mathrm{ad}} \approx 0.5$, reaches its maximum value and then decreases. In both cases (c and d) a badly defined $\beta$ peak is detected at $[\beta]_{\mathrm{ad}}>0.5$.

What can be derived from this data is that the addition of $\mathrm{Cd}$ or $\mathrm{Zn}$ to the $\beta$ domain or the inverted additions gives rise to the formation of $\mathrm{Cd}-\beta$ and $\mathrm{Zn}-\beta$ complexes in a proportion $\beta: M=1: 3$. These results are in full agreement with the structure generally accepted for the $\beta$ cluster of MT, which is able to bind three bivalent metal ions be means of its nine cysteine residues. However, the gradual formation of complexes seems to depend on the relative proportion between the metal ion and the ligand, either in the presence of excess of metal ions or in excess of ligand, particularly in the case of $\mathrm{Cd}-\beta$ complex(es). In fact, according to the electrochemical reactions previously proposed for the $\mathrm{Cd}$, $\mathrm{ZnMT}$ and for the $\mathrm{Cd}$ and $\mathrm{Zn}$ complexes with related molecules, the same compound i.e. the complexes of cadmium or zinc with the $\beta$ domain, is directly involved in the reduction reaction, $M \beta$ peak, in the same way as occurs in the oxidation reaction, $\beta(\mathrm{M})$ peak and, consequently, values of peak current should be the same for both reactions. This effectively occurs in the case of $\mathrm{Zn}-\beta$ complex in excess of $\beta$ (Fig. 2 b, $[\mathrm{Zn}]_{\mathrm{ad}}>0.5$, Fig. $\left.2 \mathrm{~d},[\beta]_{\mathrm{ad}}>0.9\right), \mathrm{Ip}_{\beta(\mathrm{Zn})} \approx \mathrm{Ip}_{\mathrm{Zn} \beta}$ and for the $\mathrm{Cd}-\beta$ complex in excess of $\mathrm{Cd}^{2+}$ (Fig. 2a, 
$[\mathrm{Cd}]_{\mathrm{ad}}>3$, Fig. $\left.2 \mathrm{~b},[\beta]_{\mathrm{ad}}<3\right), \mathrm{Ip}_{\beta(\mathrm{Cd})} \approx \mathrm{Ip}_{\mathrm{Cd} \beta}$. However when $\beta$ is in excess (Fig. $2 \mathrm{a},[\mathrm{Cd}]_{\mathrm{ad}}<1.5$, Fig. $2 \mathrm{c},[\beta]_{\mathrm{ad}}>1.0$ ), $\mathrm{Ip}_{\mathrm{Cd} \beta}>\mathrm{Ip}_{\beta(\mathrm{Cd})}$ which seems to indicate that the $\mathrm{Cd}(\mathrm{II})$ complexed by the peptide is occupying certain positions where the reduction of the cation can occur $(\mathrm{Cd} \beta$ peak) but in which $\mathrm{Cd}(\mathrm{II})$ cannot be replaced by $\mathrm{Hg}$ (II) forming the mercury dithiolate complex $(\beta(\mathrm{Cd})$ peak). In the case of zinc, with two different reduction signals, the discussion is not easy.

\section{Polarographic behaviour of the $\beta-M T$ domain during the sequential additions of cadmium and zinc simultaneously}

The sequential additions of a mixture of $\mathrm{Cd}$ and $\mathrm{Zn}$ in an equimolar proportion, $[\mathrm{Cd}]:[\mathrm{Zn}]=1: 1$, to a solution containing the $\beta$ domain were carried out with the aim of investigating the influence of one cation on the complexation of the other, when both are simultaneously present. A selection of several significant polarograms at different $[\beta]:[\mathrm{Cd}+\mathrm{Zn}]$ ratios is shown in figure $3 \mathrm{~A}$. In this figure, the new peak labelled $\mathrm{Cd} \beta$ ' is shown and is attributed to the reduction of cadmium complexed by the $\beta$ domain in a different complexation form to the $\operatorname{Cd} \beta$ one. This new peak is labelled $\mathrm{Cd} \beta$ ' by analogy with peaks named CdT and CdT' in the study of MT [8-16] and CdFT and CdFT' obtained with the peptidic fragment FT in the presence of cadmium and/or zinc [17-25] in previous electrochemical works. Peaks have been resolved as mentioned and it is necessary to point out that, when $\mathrm{Zn}^{2+}$ is in excess (Fig. 3A f), the peak potential does not coincide with the one of free $\mathrm{Zn}^{2+}$ but shifts to more positive values than are attributed to $\mathrm{Zn} \beta$ '. This behaviour was already noticed during zinc and cadmium additions to MT or FT; nevertheless the peak labelled $\mathrm{Zn}$ is not clearly associated with $\mathrm{Zn}^{2+}$ nor with a weak complex of zinc with the organic molecules [12,15,20,24].

In the evolution and predominance of species during the addition of metal ions to the $\beta$ domain, different proportions $\beta: \mathrm{M}$ can be distinguished at which different species are detected or prevalent. The initial polarogram of $\beta$ alone (Fig. 3A a) exhibits a very badly defined peak due to the $\beta$ electrochemical reaction. At 1) $[\mathrm{M}]_{\mathrm{ad}}<0.8$ corresponding to an excess of $\beta$ (Fig. 3A b), $\beta(\mathrm{Cd}), \beta(\mathrm{Zn}), \mathrm{Cd} \beta$ and $\mathrm{Zn} \beta$ are detected; $\mathrm{Ip}_{\beta(\mathrm{Cd})}, \mathrm{Ip}_{\beta(\mathrm{Zn})}$ and $\mathrm{Ip}_{\mathrm{Zn} \beta}$ increase with very similar values until $[\mathrm{M}]_{\mathrm{ad}} \approx 0.8, \beta: \mathrm{Cd}: \mathrm{Zn} \approx 1: 0.4: 0.4, \mathrm{Ip}_{\mathrm{Cd} \beta}$ grows until $[\mathrm{M}]_{\mathrm{ad}} \approx 0.4$ and remains unchanged up to $[\mathrm{M}]_{\mathrm{ad}} \approx 0.8$.

2) $0.8<[\mathrm{M}]_{\mathrm{ad}}<1.6$ at which important changes are produced (Fig. 3A d); $\mathrm{Ip}_{\beta(\mathrm{Cd})}$ increases in a gradual manner, $\beta(\mathrm{Zn})$ peak current decreases and is not observed at $[\mathrm{M}]_{\mathrm{ad}}>1.6, \mathrm{Cd} \beta$ decreases and disappears at $[\mathrm{M}]_{\mathrm{ad}} \approx 1.0$ and simultaneously, at the same proportion, $\operatorname{Cd} \beta$ ' starts to be detected and its intensity increases, $\mathrm{Zn} \beta$ decreases and $\mathrm{Zn} \beta$ ' appears at $[\mathrm{M}]_{\mathrm{ad}}>0.8$ (Fig. 3A e) and gradually increases.

3) $1.6<[\mathrm{M}]_{\mathrm{ad}}>3.0, \beta(\mathrm{Cd}), \mathrm{Cd} \beta^{\prime}$ and $\mathrm{Zn} \beta^{\prime}$ increase with slopes smaller than in 2$), \operatorname{Zn} \beta$ remains constant.

4) $[\mathrm{M}]_{\mathrm{ad}}>3.0($ Fig. $3 \mathrm{~A} \mathrm{f})$, free $\mathrm{Cd}^{2+}$ is detected and the polarogram's features are unchanged at a proportion
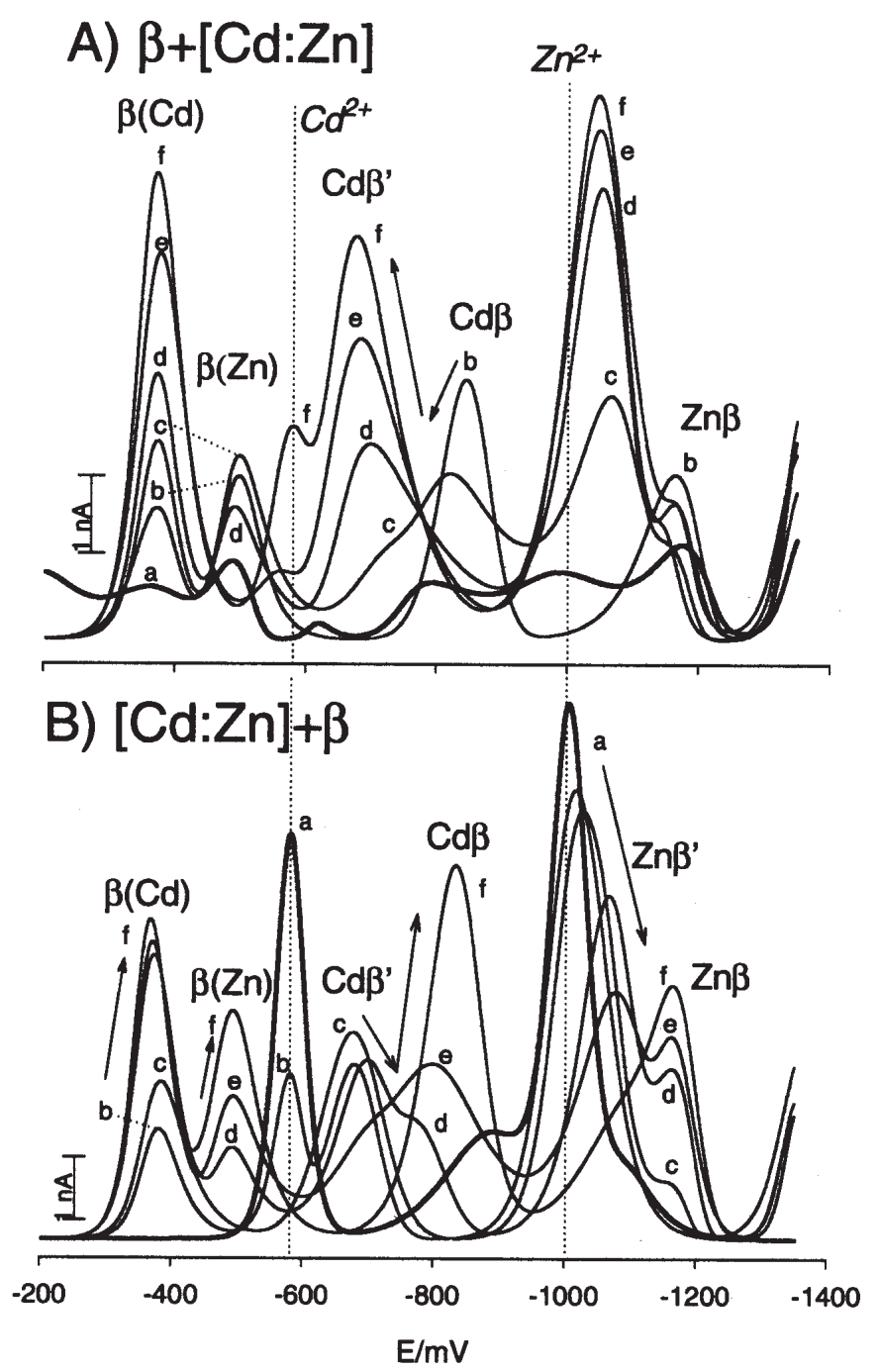

Figure 3. Polarograms obtained by sequential additions of: A) an equimolar solution of $\mathrm{Cd}$ and $\mathrm{Zn}$ to $\beta-\mathrm{MT} 5.5 \times 10^{-6} \mathrm{M}$. $\beta+[\mathrm{Cd:Zn}]$ a) 0.0 moles $\mathrm{Cd}$ and $\mathrm{Zn} /$ mole $\beta$; b) 0.6 ; c) 1.0 ; d) 1.2 ; e) 2.0 ; f) 5.0 ; and B) a $\beta$ solution to an equimolar solution of $\mathrm{Cd}$ and $\mathrm{Zn} 5 \times 10^{-6} \mathrm{M}$. [Cd:Zn] $\beta$ a) 0.0 moles $\beta /$ mole $\mathrm{Cd}$ and $\mathrm{Zn}$; b) 0.1 ; c) 0.15 ; d) 0.4 ; e) 0.45 ; f) 0.6 . Electrolyte: HEPES-phosphate buffer $10^{-2} \mathrm{M}$ at $\mathrm{pH} 8.0$.

$\beta: \mathrm{Cd}: \mathrm{Zn} \approx 1: 1.5: 1.5$ exhibiting $\beta(\mathrm{Cd}), \mathrm{Cd} \beta$ ' and $\mathrm{Zn}$ or $\mathrm{Zn} \beta$, corresponding to an excess of cations.

During the sequential addition of $\beta$ to an equimolar mixture of $\mathrm{Cd}$ and $\mathrm{Zn}$, several relations $[\beta]:[\mathrm{M}]_{\mathrm{T}}$ can also be distinguished for assessing the predominance of different species.

1) $[\beta]_{\mathrm{ad}}<0.15$ (Fig. 3B b) corresponding to an excess of cations, $\beta: \mathrm{Cd}: \mathrm{Zn} \approx 1: 3: 3$, the peak current of free $\mathrm{Cd}^{2+}$ decreases and disappears at $[\beta]_{\mathrm{ad}}>0.15$, the peak potential of free $\mathrm{Zn}^{2+}$ shifts to more negative values and its intensity 
is reduced; $\beta(\mathrm{Cd}), \mathrm{Cd} \beta$ ' and $\mathrm{Zn} \beta$ ' peaks are observed, the same as in case 4) previously described.

2) $0.15<[\beta]_{\mathrm{ad}} \leq 0.4$ (Fig. 3B c), Cd $\beta$ ' remains unchanged, $\beta(\mathrm{Cd})$ and $\mathrm{Zn} \beta$ ' increase in intensity, the latter reaching a maximum, $\beta(\mathrm{Zn})$ and $\mathrm{Zn}$ start to be detected at $[\beta]_{\mathrm{ad}}>0.3$ meaning $\beta: \mathrm{Cd}: \mathrm{Zn} \approx 1: 1.5: 1.5$. 3) $[\beta]_{\mathrm{ad}}>0.4$, when $\beta$ is in excess, $\beta(\mathrm{Cd}), \beta(\mathrm{Zn}), \mathrm{Cd} \beta$ and $\mathrm{Zn} \beta$ are observed with correspondence to case 1 ) of the inverted additions.

To compare results obtained with different types of additions the peak currents as a function either of cation additions (Fig. 4a, b, c, d) or $\beta$ additions (Fig. 4e, f, g, h) are represented with the aim of establishing similarities and differences between binary and tertiary mixtures. Vertical lines indicate the proportion either of cations or of the $\beta$ domain at which the complete complexation is produced. Therefore it is very easy to compare the range where the compounds are in excess. The appearance of free cations can be observed (Fig. 4a), the complete disappearance of $\mathrm{Cd}^{2+}$ and $\mathrm{Zn}^{2+}$ signals (Fig. $4 \mathrm{c}$ ) occur at the same proportion $\beta: \mathrm{M} \approx 1: 3$ independently of whether the metal ions are present either alone or together. However the predominance of other electrochemical responses depends on whether or not the cations are present alone or together. So, concerning anodic responses, while $\beta(\mathrm{Cd})$ and $\beta(\mathrm{Zn})$ behave in a similar manner with comparable variation for binary mixtures, when $\beta$, $\mathrm{Cd}$ and $\mathrm{Zn}$ are together, the only peak observed is the one corresponding to $\beta(\mathrm{Cd})$ at given proportions. In fact $\beta(\mathrm{Cd})$ is the only one due to the oxidation of the mercury electrode when cations are in excess and $\beta$ is under its complexed form. $\beta(\mathrm{Cd})$ seems to be related with the detection of $\mathrm{Cd} \beta$ ' (Fig. $4 \mathrm{c}$ and g) or $\mathrm{Cd} \beta$ (Fig. $4 \mathrm{~d}$ and b), whereas $\beta(\mathrm{Zn})$ is observed at excess of $\beta$ (Fig. $4 b$ and $f$ ); $\beta(\mathrm{Zn})$ increases with a slope similar to $\beta(\mathrm{Cd})$ at $[\mathrm{M}]_{\mathrm{ad}} / \mathrm{mol} \beta<1$ and disappears at $[\mathrm{M}]_{\mathrm{ad}}>1$ (Fig. $4 \mathrm{~b}$ ) or is detected at $[\beta]_{\mathrm{ad}}>0.3$ and increases with the same slope as $\beta(\mathrm{Cd})$ (Fig. 4f). The detection of $\beta(\mathrm{Zn})$ seems to be related to the $\mathrm{Zn} \beta$ detection and not to $\mathrm{Zn} \beta$,', when both cations, $\mathrm{Cd}$ and $\mathrm{Zn}$, are present. Therefore, $\mathrm{Hg}$ (II) can replace the metal ions when they are occupying certain sites in the molecule corresponding to the complexation form with $\mathrm{Zn} \beta$ and $\operatorname{Cd} \beta$ responses. So, the $\beta(\mathrm{Zn})$ peak disappears (Fig. 4b) when the $\mathrm{Cd} \beta$ ' or $\mathrm{Zn} \beta$ ' signals reach a maximum (Fig. 4c) at a proportion coinciding with the decreasing or the disappearance of responses due to $\mathrm{Cd} \beta$ and $\mathrm{Zn} \beta$ (Fig. 4d) and it appears (Fig. 4f) when, $\mathrm{Cd} \beta$ and $\mathrm{Zn} \beta$ start to be detected (Fig. 4h) or when, $\mathrm{Cd} \beta$ ' and $\mathrm{Zn} \beta$ ' simultaneously decrease and then disappear (Fig. 4g).

In addition, $\mathrm{Cd} \beta$ ' and $\mathrm{Zn} \beta$ ' are interrelated and are the prevalent peaks of the metal ion reduction, when they are in excess in relation to $\beta$ (Fig. $4 \mathrm{c}$ and g) whereas $\operatorname{Cd} \beta$ and $\mathrm{Zn} \beta$ are the major ones when, $\beta$ is in excess (Fig. $4 d$ and $h$ ).

Summarising all results (Fig. 4) it can be concluded that in an excess of $\beta$ and in the simultaneous presence of both metal ions the polarographic response is $\beta(\mathrm{Cd}), \beta(\mathrm{Zn}), \mathrm{Cd} \beta$ and $\mathrm{Zn} \beta$, probably corresponding to the pure complexation forms of $\beta$ with cadmium and zinc, and, in an excess of metal ions, when the limiting concentration is the $\beta$ one, a reorganisation of the form of complexation into the mole- cules is produced, probably leading to the form of cadmium and zinc mixed complexes (vide infra); in this case polarograms exhibit $\beta(\mathrm{Cd}), \mathrm{Cd} \beta$ ' and $\mathrm{Zn} \beta$ ' peaks.

\section{Polarographic behaviour of the $\beta$ MT domain during sequential additions of one metal ion, cadmium or zinc followed by additions of the other i.e. zinc or cadmium}

After having added one of the metal ions to the $\beta$ cluster and the inverted additions, (vide supra Figs. 1 and 2) the addition of the other ion was carried out with the aim of studying the influence of one cation on the complexation of the other and of comparing this behaviour with results obtained adding both cations together.

Once $3.5 \mathrm{~mol} \mathrm{Cd} / \mathrm{mol} \beta$ have been added to a $\beta$ solution (Fig. $1 \mathrm{~A} \mathrm{f}$ and $5 \mathrm{~A} \mathrm{f}$ ), the gradual addition of zinc was performed. The evolution of polarograms is illustrated in figure 5A. The initial polarogram (Fig. 5A f) exhibits the following peaks: $\beta(\mathrm{Cd}), \mathrm{Cd}^{2+}$ and $\mathrm{Cd} \beta$. The addition of zinc provokes the gradual transformation of the $\operatorname{Cd} \beta$ peak initially present into the $\mathrm{Cd} \beta$ ' peak, as well as causing the detection of the $\mathrm{Zn}(\mathrm{II})$ reduction peaks, $\mathrm{Zn} \beta$ ' and $\mathrm{Zn} \beta$ peaks but not the oxidation peak $\beta(\mathrm{Zn})$.

Fig. 5B shows various significant polarograms of $\mathrm{Cd}$ additions to a mixture containing $\beta: \mathrm{Zn}$ at a proportion $1: 3.5$, with $\mathrm{Zn}^{2+}$ in excess. The initial peaks (Fig. $1 \mathrm{~B} d$ and Fig. 5B d) are: $\beta(\mathrm{Zn}), \mathrm{Zn}^{2+}, \mathrm{Zn} \beta$ ' and $\mathrm{Zn} \beta$. The addition of cadmium produces the diminishing and then the disappearance of $\beta(\mathrm{Zn})$ and the increase of the reduction peak of $\mathrm{Cd}(\mathrm{II})$ in the form $\mathrm{Cd} \beta$ '.

The variation of the peak current of all species is represented as a function of metal concentration added (Fig. 6). In this figure, the $\mathrm{Cd}^{2+}$ peak current $(\sim 4 \mathrm{nA})$ and the one of $\mathrm{Zn}^{2+}(\sim 3 \mathrm{nA})$ are not represented. It is observed (Fig. 6a) that $\mathrm{Ip}_{\beta(\mathrm{Cd})}$ remains constant for all values of $[\mathrm{Zn}]_{\mathrm{ad}}, \mathrm{Cd} \beta$ ' and $\mathrm{Zn} \beta$ ' peaks increase with similar intensity values and $\mathrm{Zn} \beta$ remains unchanged with a final intensity $\mathrm{Ip}_{\mathrm{Zn} \beta} \approx 1 / 5 \mathrm{Ip}_{\mathrm{Zn} \beta}$. $\mathrm{Cd} \beta$ linearly decreases with the same slope as obtained for the addition of $\mathrm{Cd}$ alone to $\beta$ (Fig. $2 \mathrm{a}$ ). The complete disappearance of $\mathrm{Cd} \beta$ peak requires the addition of $\approx 1 \mathrm{~mol}$ $\mathrm{Zn} / \mathrm{mol} \mathrm{Cd}$. In the case of zinc additions (Fig. $6 \mathrm{~b}$ ) the disappearance of $\beta(\mathrm{Zn})$ is clearly observed and occurs for the same proportion of added $\mathrm{Cd}$ as free $\mathrm{Cd}^{2+}$ starts to be detected. $\beta(\mathrm{Cd})$ and $\mathrm{Cd} \beta$ increase in a similar manner; $\operatorname{Ip}_{\mathrm{Zn} \beta}$, slightly decrease until reaching the same intensity value as $\mathrm{Ip}_{\mathrm{Cd} \beta}$. $\mathrm{Zn} \beta$ remains constant. In both kinds of additions, $\beta+$ $\mathrm{Cd}+\mathrm{Zn}$ and $\beta+\mathrm{Zn}+\mathrm{Cd}$, free cations are detected for the same proportion $\beta: \mathrm{Cd}: \mathrm{Zn} \approx 1: 2-3: 2-3$. The final feature, when metal ions are in excess, is also the same: $\beta(\mathrm{Cd}) \approx \mathrm{Cd} \beta^{\prime} \approx \mathrm{Zn} \beta^{\prime}>\mathrm{Zn} \beta$ and similar to that obtained when both cations are added together, and are in excess (Fig. 4).

The same type of experiments, after addition of $\beta$ to the solutions of $\mathrm{Cd}$ or $\mathrm{Zn}$ separately was carried out. In this case, there is a great excess of $\beta$, about 1.7 and $1.5 \mathrm{~mol}$ $\beta / \mathrm{mol} \mathrm{Cd}$ or $\mathrm{Zn}$, respectively. The evolution of peak 


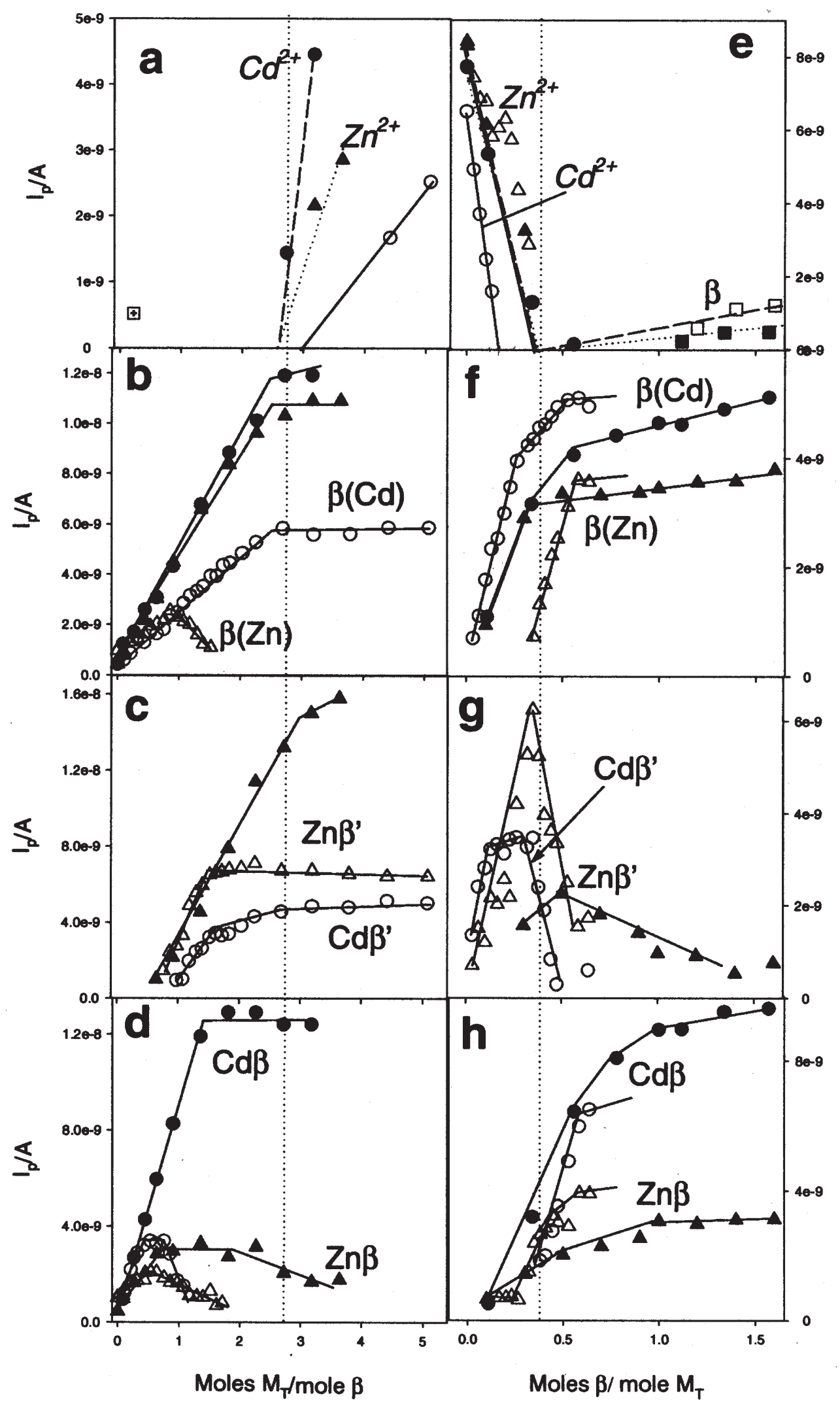

Figure 4. Peak currents obtained for all peaks when: $\mathrm{Cd}(\bullet), \mathrm{Zn}(\mathbf{\Delta})$, or an equimolar solution of $\mathrm{Cd}$ and $\mathrm{Zn}$ $((O)$ for $\mathrm{Cd}(\mathrm{II})$ peaks and $(\Delta)$ for $\mathrm{Zn}$ (II) peaks) were added to a solution of $\beta$-MT $5.5 \times 10^{-6} \mathrm{M}(\mathrm{a}, \mathrm{b}, \mathrm{c}, \mathrm{d})$; and when $\beta$ is added to $\mathrm{Cd}(\bullet)$, $\mathrm{Zn}(\mathbf{\Delta})$, or an equimolar solution of $\mathrm{Cd}$ and $\mathrm{Zn}((\bigcirc)$ for $\mathrm{Cd}(\mathrm{II})$ peaks, and $(\Delta)$ for $\mathrm{Zn}$ (II) peaks), being the initial concentration of all cations in solution $5 \times 10^{-6} \mathrm{M}(\mathrm{e}, \mathrm{f}, \mathrm{g}$, h). Electrolyte: HEPES-phosphate buffer $10^{-2} \mathrm{M}$ at $\mathrm{pH}$ 8.0.

ANALUSIS, 2000, 28, № 5 (c) EDP Sciences, Wiley-VCH 2000 


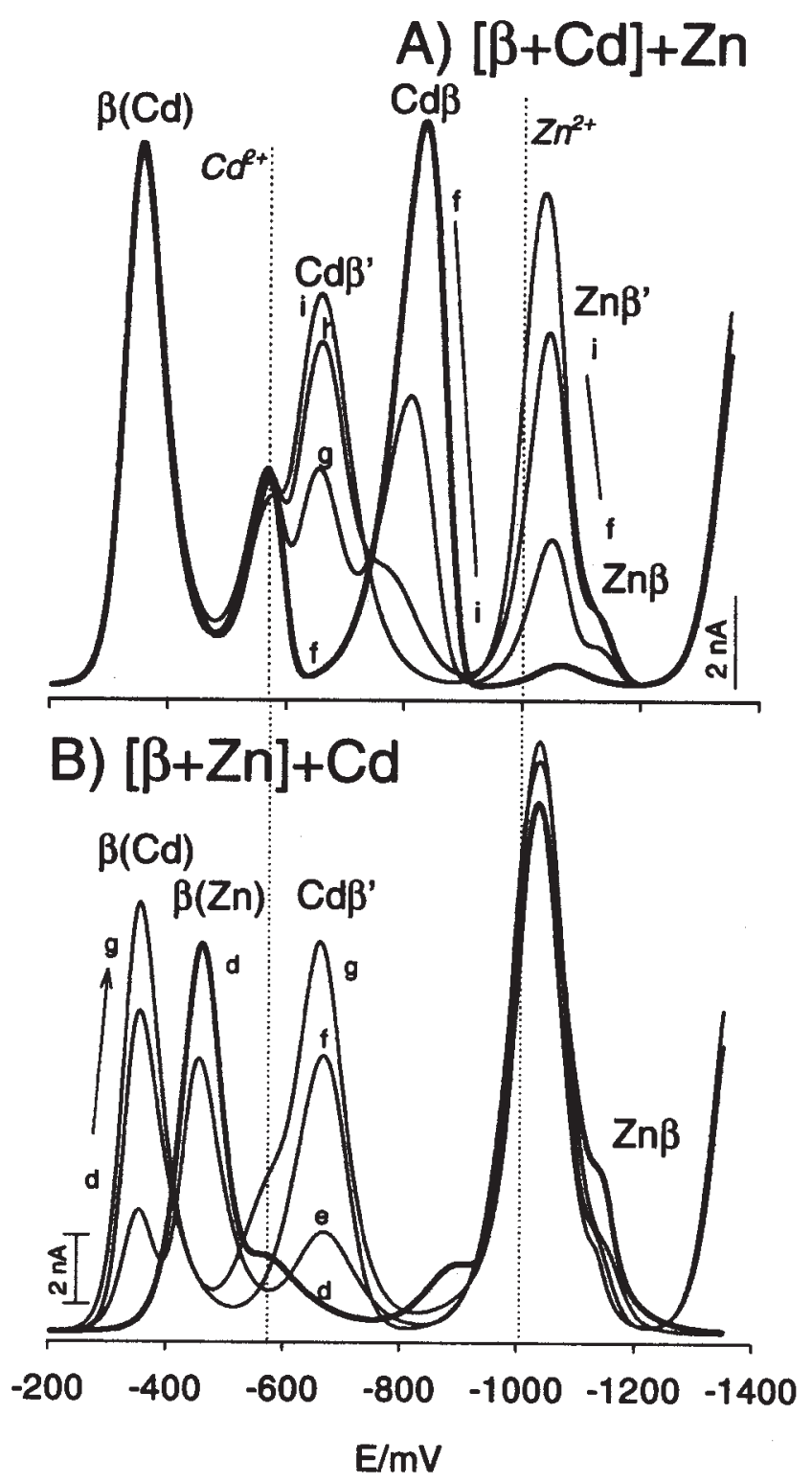

Figure 5. Polarograms corresponding to the sequential addition of $X \mathrm{~mol} / \mathrm{mol} \beta$ of one cation, $\mathrm{Cd}$ or $\mathrm{Zn}$, to a solution containing both $\beta$-MT $5.5 \times 10^{-6} \mathrm{M}$ and an excess of the other cation, $\mathrm{Zn}$ or Cd. A) Addition of $\mathrm{Zn}$ to $\beta+3.2 \mathrm{moles} \mathrm{Cd} / \mathrm{mol} \beta$, f) 0 moles $\mathrm{Zn} / \mathrm{mol} \beta$; g) 0.6 ; h) 1.4 ; i) 3.2 ; B) Addition of $\mathrm{Cd}$ to $\beta+3.2$ moles $\mathrm{Zn} / \mathrm{mol} \beta$, d) 0 moles $\mathrm{Cd} / \mathrm{mol} \beta$; e) 0.6 ; f) 1.4; g) 3.2. HEPES-phosphate buffer $10^{-2} \mathrm{M}$ at $\mathrm{pH} 8.0$.

intensity for the binary mixtures is that represented in figure $2 \mathrm{c}$ and $\mathrm{d}$. Likewise, another experiment of $\beta$ addition to a $\mathrm{Zn}$ solution with a slight excess of $\beta$ was performed $(\sim 0.5 \mathrm{~mol} \beta / \mathrm{mol} \mathrm{Zn})$.

To summarise, the behaviour of the tertiary mixtures in all additions, the peak currents are represented in figure 7 , in which vertical lines indicate the concentration of free $\beta$. It is clearly seen (Fig. 7a) that for a proportion of added

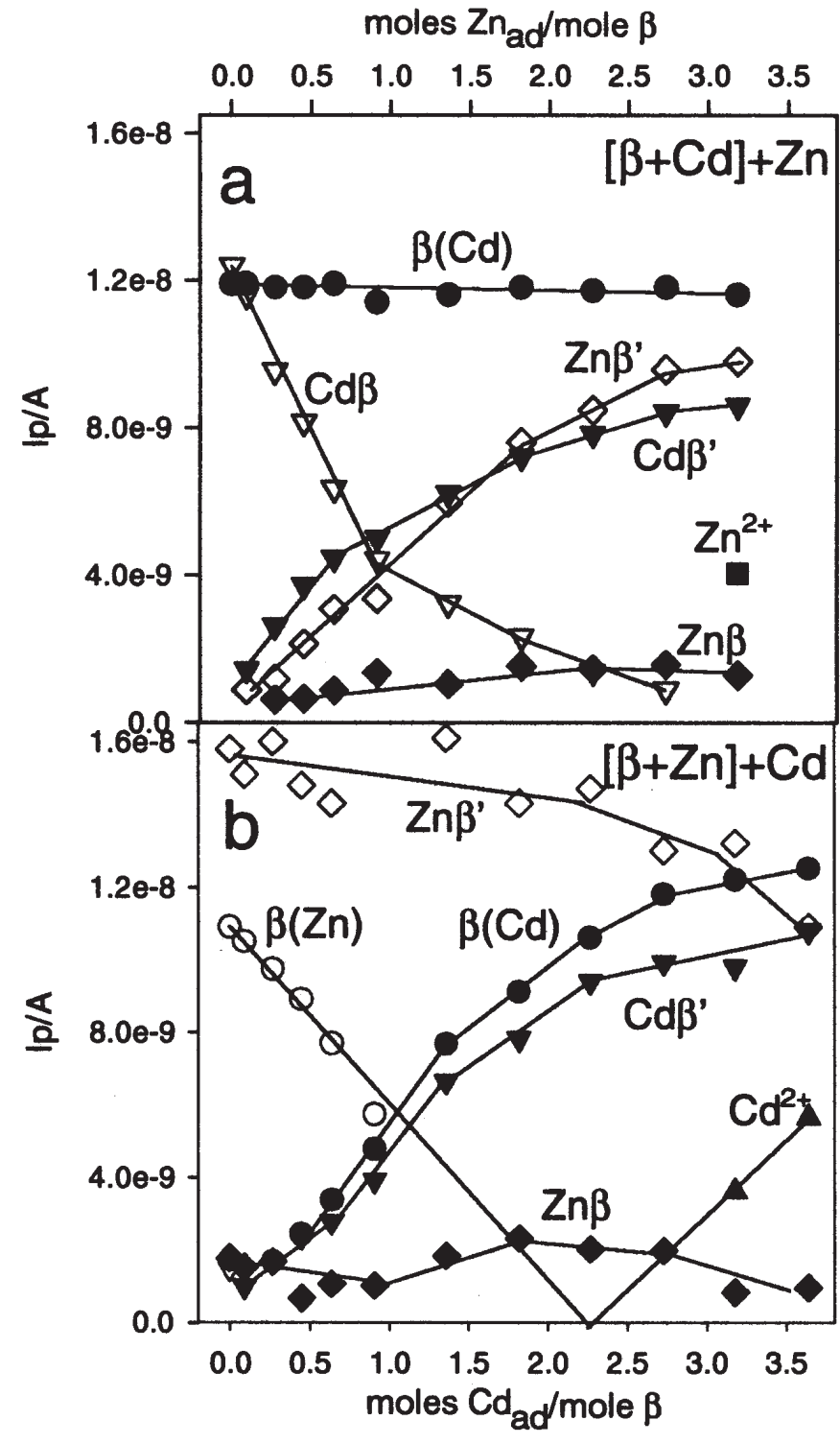

Figure 6. Peak currents for all species obtained when $\mathrm{Cd}$ or $\mathrm{Zn}$ were added gradually to a solution containing both $\beta$-MT $5.5 \times 10^{-6} \mathrm{M}$ and an excess of the other cation, $\mathrm{Zn}$ or $\mathrm{Cd}$. a) Addition of $\mathrm{Zn}$ to $\beta+3.2 \mathrm{moles} \mathrm{Cd} / \mathrm{mol} \beta$, and b) addition of Cd to $\beta+3.2$ moles $\mathrm{Zn} /$ mole $\beta$. HEPES-phosphate buffer $10^{-2} \mathrm{M}$ at $\mathrm{pH} 8.0$.

$\mathrm{Zn}<2$, which corresponds to that of free $\beta$, the evolution of peaks is analogous to that already presented in figure $2 b$ for $\beta(\mathrm{Zn})$ and $\mathrm{Zn} \beta$ peaks; in this concentration range $\beta(\mathrm{Cd})$ and $\mathrm{Cd} \beta$ remain unchanged because the complexation of zinc with free $\beta$ does not affect them. However for $[\mathrm{Zn}]_{\mathrm{ad}}>1.8$ the peak evolution is similar to that shown in Fig. $6 a, \beta(\mathrm{Cd})$ remains constant, $\mathrm{Cd} \beta$ is not detected at $[\mathrm{Zn}]_{\mathrm{ad}}>4$, which is the same proportion at which $\mathrm{Cd} \beta$ ' starts to be detected (not shown). 
When cadmium is added to a solution containing $\mathrm{Zn}+\beta$, in which $\beta$ is in a great excess (Fig. 7b) or small excess (Fig. 7b') two ranges of proportion can also be distinguished; for $[\mathrm{Cd}]_{\mathrm{ad}}<1.5 \mathrm{~mol} \beta / \mathrm{mol} \mathrm{Zn} \mathrm{(Fig.} \mathrm{7b)} \mathrm{or}$ $[\mathrm{Cd}]_{\mathrm{ad}}<0.5 \mathrm{~mol} \beta / \mathrm{mol} \mathrm{Zn} \mathrm{(Fig.} \mathrm{7b')} \mathrm{the} \mathrm{variation} \mathrm{of} \mathrm{peak}$ currents is very similar to that of the binary mixtures represented in figure 2 a meaning $\beta(\mathrm{Cd})$ and $\mathrm{Cd} \beta$ increase, $\beta(\mathrm{Zn})$ and $\mathrm{Zn} \beta$ remain constant. When the added $\mathrm{Cd}$ is in excess of the free $\beta$, the evolution of species depends on the initial proportion of $\beta$ as well as on the metal ions ratio. So, $\operatorname{Cd} \beta$ remains unchanged (Fig. 7b) but decreases in the case of slight excess of $\beta$ (Fig. 7b'). Cd $\beta$ ' starts to be detected at $[\mathrm{Cd}]_{\mathrm{ad}}>2.5$ and $[\mathrm{Cd}]_{\mathrm{ad}}>0.5$ in figure $7 \mathrm{~b}$ and $7 \mathrm{~b}$, respectively. Free $\mathrm{Cd}^{2+}$ is observed at different cation ratios, $\beta: \mathrm{Cd}: \mathrm{Zn} \approx 1.8: 3.5: 1$ (Fig. 7b) and 0.8:3:1 (Fig. 7b'). The variation of $\mathrm{Zn}$ peaks is similar in both figures.

\section{Influence of the $\mathrm{pH}$ on the complexation forms of cadmium}

In previous DPP studies with MT [10,11,13,16] and with FT:Cd:Zn $[19,20,25]$, the variation of $\mathrm{pH}$ has been seen to play an important role in the stability of one of the two cadmium complexes, CdT and CdT', and CdFT and CdFT'; in fact it is possible to provoke a change or to modify the proportion of both complexes by a mere change of the solution $\mathrm{pH}$. When the $\mathrm{pH}$ is increased from 8 to 9.5 the transformation of CdT' peak, obtained in the presence of zinc, into the CdT peak occurs. Using different tertiary mixtures $\beta: \mathrm{Cd}: \mathrm{Zn}$ the effect of changing $\mathrm{pH}$ has been studied. For a given proportion, the only peak detected is $\mathrm{Cd} \beta^{\prime}$ at $\mathrm{pH} 8$ for the reduction of $\mathrm{Cd}(\mathrm{II})$ (Fig. $8 \mathrm{~A}$ and $\mathrm{B}$, polarogramme a). When the $\mathrm{pH}$ is increased to higher than 9 , the total disappearance of the $\mathrm{Cd} \beta$ ' complex is observed as well as the simultaneous appearance of $\mathrm{Cd} \beta$ (Fig. 8A and 8B, polarogramme b). Whereas for several MT the equilibrium CdT $\leftrightarrow$ CdT' is reversible and quickly reached [10], in the case of $\beta: \mathrm{Cd}: \mathrm{Zn}$ mixtures the equilibrium between $\operatorname{Cd} \beta$ and $\operatorname{Cd} \beta$ ' is not reversible and, hence, $\mathrm{Cd} \beta$ ' is not detected when the $\mathrm{pH}$ is readjusted to 8 ; moreover the signals due to the $\mathrm{Zn}$ (II) reduction are not observed at more basic $\mathrm{pH}$ and are also not detected at the readjusted $\mathrm{pH}$.

\section{Comparison between the polarographic results and those obtained using electrospray ionisation mass spectrometry}

Several determinations of the stoichiometry of compounds in different binary mixtures $\beta: \mathrm{Cd}$ and $\beta: \mathrm{Zn}$ and tertiary mixtures $\beta: \mathrm{Cd}: \mathrm{Zn}$ at different metal ion to ligand proportions has been performed by our team using electrospray ionisation mass spectrometry under similar experimental conditions [35] as those carried out using electrochemical methods. The aim of this study is to make a comparison between results obtained using two different methods. The experimental conditions used in the application of both methods are not identical because the electrochemical measurements were performed in each solution after gradual additions of one compound to another, with slight variations of chemical composition, whereas in the case of the MS study, different
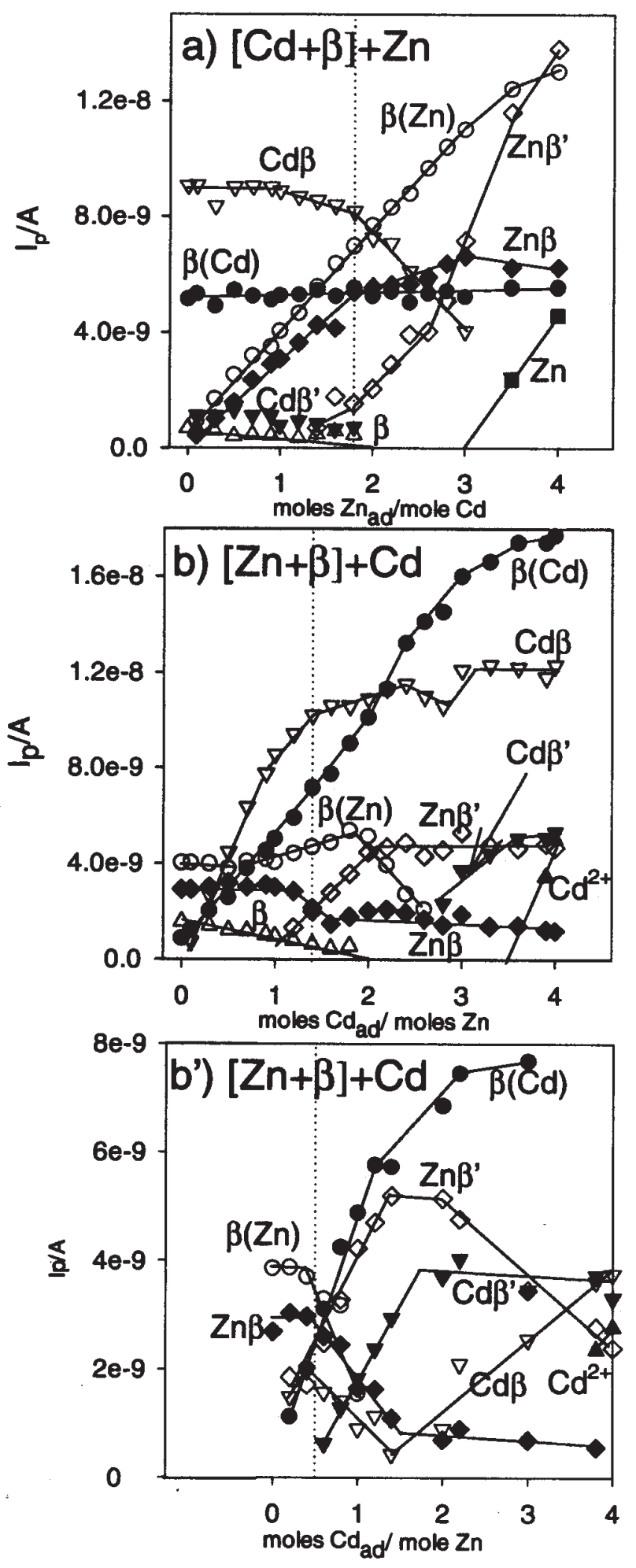

Figure 7. Peak currents for all species obtained when $\mathrm{Cd}$ or $\mathrm{Zn}$ were added gradually to a solution containing the other cation, $\mathrm{Zn}$ or $\mathrm{Cd}, 5 \times 10^{-6} \mathrm{M}$, and an excess of $\beta-M T$. a) addition of $\mathrm{Zn}$ to $\mathrm{Cd}+\mathbf{2 . 2}$ moles $\beta /$ mole $\mathrm{Cd}$, b) addition of $\mathrm{Cd}$ to $\mathrm{Zn}+$ $1.8 \mathrm{~mol} \beta / \mathrm{mol} \mathrm{Zn}$, and $b^{\prime}$ ) addition of $\mathrm{Cd}$ to $\mathrm{Zn}+0.9 \mathrm{~mol} \beta / \mathrm{mol}$ $\mathrm{Zn}$. HEPES-phosphate buffer $10^{-2} \mathrm{M}$ at $\mathrm{pH} 8.0$. 
mixtures of a given composition have been prepared and immediately measured. In addition, it should be pointed out that the MS signals are very well defined for binary mixtures $\beta: \mathrm{Cd}$ and $\beta: \mathrm{Zn}$, but for tertiary mixtures, for which responses from cadmium and zinc complexes are simultaneously obtained, due to a better definition of cadmium responses than in the case of zinc, the composition of zinc compounds or even their presence, cannot be measured in a precise way.

The MS results are summarised as follows in order to make comparisons:
$\beta: \mathrm{Cd}$
$1: 0$ to $1: 4$
$[\mathrm{Cd}] \leq 3, \mathrm{Cd}_{2} \beta, \mathrm{Cd}_{3} \beta$,
$[\mathrm{Cd}] \geq 3, \mathrm{Cd}_{3} \beta, \mathrm{Cd}_{4} \beta$
$\beta: \mathrm{Zn} ; \quad 1: 0$ to $1: 4 \quad \mathrm{Zn}_{3} \beta$
$\beta+[\mathrm{Cd}+\mathrm{Zn}] ; \quad 1: 1: 1$ to $1: 3: 3 \quad \mathrm{Cd}_{2} \mathrm{Zn}_{1} \beta, \mathrm{Cd}_{1} \mathrm{Zn}_{2} \beta$
$\beta+\mathrm{Cd}+\mathrm{Zn}$ or $\beta+\mathrm{Zn}+\mathrm{Cd}$
$\beta: \mathrm{Cd}: \mathrm{Zn}$,

$$
\begin{array}{ll}
\text { 1:3:1, 1:3:2, 1:3:3 } & \mathrm{Cd}_{3} \beta, \mathrm{Cd}_{4} \beta \\
1: 2: 1,1: 2: 2 & \mathrm{Cd}_{3} \beta, \mathrm{Cd}_{2} \mathrm{Zn}_{1} \beta, \mathrm{Cd}_{1} \mathrm{Zn}_{2} \beta ; \\
1: 1: 2,1: 1: 3 & \mathrm{Cd}_{2} \mathrm{Zn}_{1} \beta, \mathrm{Cd}_{1} \mathrm{Zn}_{2} \beta, \mathrm{Zn}_{3} \beta
\end{array}
$$

From MS results the assignment of polarographic peaks to possible complexes could be carried out. For the binary mixtures $\beta+\mathrm{Cd}$ and $\mathrm{Cd}+\beta$ (Fig. $2 \mathrm{a}$ and b and Fig. 4) the only peak of the $\mathrm{Cd}(\mathrm{II})$ reduction detected, $\mathrm{Cd} \beta$, should correspond to the $\mathrm{Cd}_{3} \beta$ complex in an excess of ligand and to a mixture of $\mathrm{Cd}_{3} \beta$ or $\mathrm{Cd}_{4} \beta$, when the cation is in excess, with peak potentials similar or very close to the reduction of cadmium contained in the two complexes. However the position occupied by the cadmium in the molecule may be different because the intensity of the reduction peak is twice the anodic one (Fig. 2c), which seems to indicate that the mercury (II) arising from the oxidation of the electrode could replace cadmium only in given positions. For the $\beta+\mathrm{Zn}$ and $\mathrm{Zn}+\beta$ mixtures (Fig. $2 \mathrm{~b}$ and d, Fig. 4) the two reductions $\mathrm{Zn}(\mathrm{II})$ peaks correspond to only one complex $\mathrm{Zn}_{3} \beta$; nevertheless $\mathrm{Zn} \beta$ is the prevalent peak in excess of ligand and associated to $\beta(\mathrm{Zn})$. When zinc is in excess, $[\beta] /[\mathrm{Zn}]<0.75$, the predominant peak is $\mathrm{Zn} \beta$ '. Under the latter conditions the accessibility of $\mathrm{Zn}$ (II) to the electrode is bigger in reduction than in oxidation, $\mathrm{Ip}_{\mathrm{Zn} \beta},+\mathrm{Ip}_{\mathrm{Zn} \beta}>\mathrm{Ip}_{\beta(\mathrm{Zn})}$ (Fig. 2b).

In the case of additions of both cations together to the $\beta$ domain or the inverted additions, two different conditions, as already mentioned, can be clearly distinguished (Fig. 4): an excess of ligand with the associated polarographic peaks: $\beta(\mathrm{Cd}), \beta(\mathrm{Zn}), \mathrm{Cd} \beta$ and $\mathrm{Zn} \beta$, having intensity values in reduction $\left(\mathrm{Ip}_{\mathrm{Cd} \beta}+\mathrm{Ip}_{\mathrm{Zn} \beta} \approx 9.9 \mathrm{nA}\right)$ similar to oxidation peaks $\left(\mathrm{Ip}_{\beta(\mathrm{Cd})}+\mathrm{Ip}_{\beta(\mathrm{Zn})} \approx 9.1 \mathrm{nA}\right)$. When the metal ions are in excess, the polarographic features are as follows $\beta(\mathrm{Cd}), \mathrm{Cd} \beta$ ' and $\mathrm{Zn} \beta$, , with an anodic intensity $\left(\operatorname{Ip}_{\beta(\mathrm{Cd})} \approx 5.7 \mathrm{nA}\right)$ the half of the total cathodic current $\left(\operatorname{Ip}_{\mathrm{Cd} \beta},+\operatorname{Ip}_{\mathrm{Zn} \beta}, \approx 11.4 \mathrm{nA}\right)$. For tertiary mixtures $\beta+[\mathrm{Cd}+\mathrm{Zn}]$, the complexes identified using $\mathrm{MS}$ are mixed cadmium and zinc complexes, $\mathrm{Cd}_{2} \mathrm{Zn}_{1}$ and $\mathrm{Cd}_{1} \mathrm{Zn}_{2}$, in different proportions and consequently the $\mathrm{Cd} \beta$ '

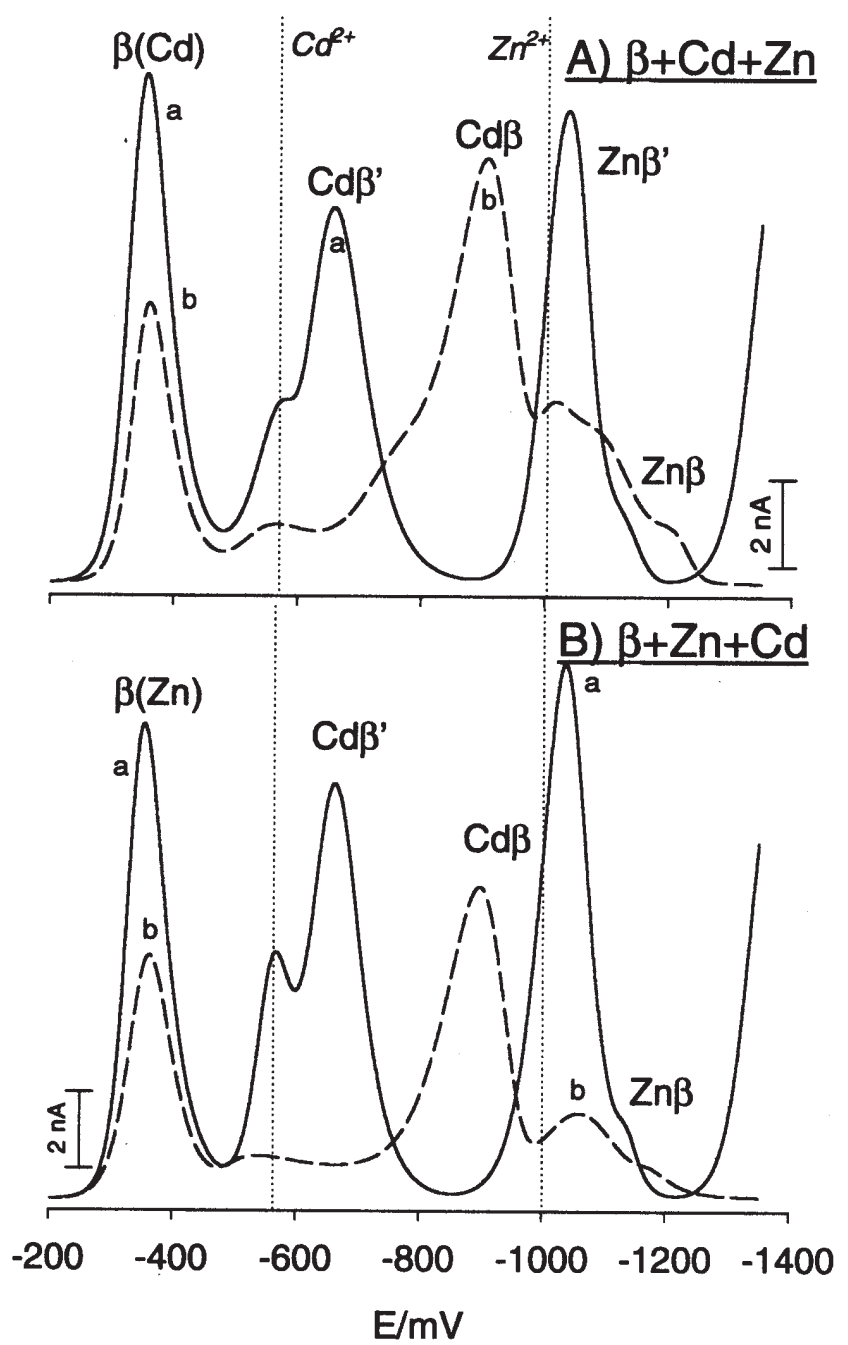

Figure 8. Polarograms obtained after addition of $\mathrm{Cd}$ and $\mathrm{Zn}$ to a $\beta$-MT solution $5 \times 5 \times 10^{-5} \mathrm{M}$. a) $\mathrm{pH}=8$, b) $\mathrm{pH}=8.9$. A) $\beta+3.5 \mathrm{Cd}+3.5 \mathrm{~mol} \mathrm{Zn} / \mathrm{mol} \beta$ B) $\beta+4.0 \mathrm{Cd}+4.0 \mathrm{~mol} \mathrm{Zn}$ /mol $\beta$. HEPES-phosphate buffer $10^{-2} \mathrm{M}$.

and $\mathrm{Zn} \beta$ ' peaks could be related to the reduction of cations in the form of mixed complexes. However, the lack of detection of the $\beta(\mathrm{Zn})$ peak at a given ratio of cadmium and zinc seems to indicate that $\mathrm{Zn}$ (II) is replaced by $\mathrm{Hg}$ (II) only when it is in the $\mathrm{Zn} \beta$ form but not in the $\mathrm{Zn} \beta$ ' form and hence this metal ion has a different position in the molecule from cadmium in this kind of complexes.

Concerning the tertiary mixtures for which $\operatorname{Cd} \beta$ and $\operatorname{Cd} \beta$ ' peaks are simultaneously observed, MS results showed both pure cadmium complexed, $\mathrm{Cd}_{3} \beta$ and $\mathrm{Cd}_{4} \beta$ and mixed complexes $\mathrm{Cd}_{2} \mathrm{Zn}_{1} \beta$ and $\mathrm{Cd}_{1} \mathrm{Zn}_{2} \beta$ which confirms the attribution of the $\mathrm{Cd} \beta$ peak to $\mathrm{Cd}_{3} \beta$ or $\mathrm{Cd}_{4} \beta$ complexes and the $\mathrm{Cd} \beta$, to $\mathrm{Cd}_{2} \mathrm{Zn}_{1} \beta$ or $\mathrm{Cd}_{1} \mathrm{Zn}_{2} \beta$. So for $\beta+\mathrm{Zn}+\mathrm{Cd}$ (Fig. 6b) 1:2.5:3.5 with polarographic peaks $\beta(\mathrm{Cd})>\mathrm{Cd} \beta^{\prime} \approx \mathrm{Zn} \beta$, the MS results, for a similar proportion, correspond to $\mathrm{Cd}_{2} \mathrm{Zn}_{1} \beta$ 
and $\mathrm{Cd}_{1} \mathrm{Zn}_{2} \beta$ complexes or in the case of $\beta+\mathrm{Cd}+\mathrm{Zn}, 1: 3: 1$, exhibiting peaks $\beta(\mathrm{Cd}), \quad \mathrm{Cd} \beta \approx \mathrm{Cd} \beta^{\prime} \approx \mathrm{Zn} \beta^{\prime}>\mathrm{Zn} \beta$ (Fig. 7b') $\mathrm{Cd}_{3} \beta$ and $\mathrm{Cd}_{2} \mathrm{Zn}_{1} \beta$ complexes are detected by MS.

At this stage it is perhaps necessary to clarify that, in the case of cadmium complexes, both the electrochemical and MS responses are well defined allowing an unambiguous distinction between $\mathrm{Cd}^{2+}, \mathrm{Cd} \beta$ ' and $\mathrm{Cd} \beta$ peaks in the polarographic study or between pure cadmium complexes $\mathrm{Cd}_{3} \beta$ and $\mathrm{Cd}_{4} \beta$ and mixed complexes $\mathrm{Cd}_{2} \mathrm{Zn}_{1} \beta$ and $\mathrm{Cd}_{1} \mathrm{Zn}_{2} \beta$. Concerning $\mathrm{Zn}$ compounds the polarographic peaks attributed to different species are very close to each other and the resolution of the signal is carried out using an "artificial approach". The corresponding signals in the MS spectra are also poorly defined.

\section{Influence of the $\mathrm{pH}$}

For several tertiary mixtures $\beta+[\mathrm{Cd}+\mathrm{Zn}]$ the MS determinations were carried out at $\mathrm{pH} 8$ and $\mathrm{pH} 9$ in order to get more information on the stability of $\operatorname{Cd} \beta$ ' and $\operatorname{Cd} \beta$ forms at these two different $\mathrm{pH}$ (see Fig. 8). On the basis of MS data, for $\beta: \mathrm{Cd}: \mathrm{Zn}, 1: 2: 2,1: 3: 3$ the existence of $\mathrm{Cd}_{2} \mathrm{Zn}_{1} \beta$ and $\mathrm{Cd}_{1} \mathrm{Zn}_{2} \beta$ complexes is assumed at $\mathrm{pH} 8$, whereas for the same mixtures at $\mathrm{pH} 9$ the only identified complexes are $\mathrm{Cd}_{3} \beta$ and $\mathrm{Cd}_{4} \beta$, the latter in higher proportion for the $1: 3: 3$ relation. Thus, the dependence of the complexed form on the solution $\mathrm{pH}$ effectively confirms that $\mathrm{Cd} \beta$ polarographic peak is due to pure complexes while $\mathrm{Cd} \beta$ ' peak is associated with mixed complexes. Likewise, the fact that zinc complex(es) are not detected using DPP or MS, at $\mathrm{pH} 9$ could be explained by the possible displacement of zinc initially bound to the $\beta$ fragment when $\mathrm{Cd}$ is added and the further precipitation of $\mathrm{Zn}^{2+}$ as hydroxide at the more basic $\mathrm{pH}$. Cadmium forms more stable complexes with the $\beta$ domain than zinc; consequently the cadmium should remove the zinc bound to the thiol groups in the molecule, at $\mathrm{pH} 9$, to the detriment of the fraction of cadmium, zinc complexes at $\mathrm{pH} 8$.

\section{Estimation of apparent stability constants $\beta-M$}

The apparent stability constants of $\mathrm{Cd}-\beta, \mathrm{Zn}-\beta$ and $\mathrm{Hg}-\beta$ complexes have been evaluated using previously described approaches $[8,17,18]$. In the case of $\mathrm{Cd}-\beta$ and $\mathrm{Zn}-\beta$ the differences between the potential of free cations and the complexed ions have been taken from polarograms recorded in the case of binary mixtures. For the evaluation of $\mathrm{Hg}-\beta$ constants the difference of potentials between the oxidation of mercury in the supporting electrolyte (unlimited current in oxidation) and the oxidation of the mercury in the presence of the $\beta$ domain alone was used. The concentration of the ligand, included in the stability constants value, was taken as being approximately $10^{-5} \mathrm{M}$.

The $\log \mathrm{K}_{\mathrm{Cd} \beta}^{\prime}, \log \mathrm{K}_{\mathrm{Zn} \beta}^{\prime}$ and $\log \mathrm{K}_{\mathrm{Hg} \beta}$ values are 14,9 and 34 , respectively. These values are comparable to those obtained for Cd, ZnMT of different origin [8,9,11] and for M-FT complexes [18-20], M being $\mathrm{Cd}, \mathrm{Zn}$ or $\mathrm{Hg}$. Even if the assumption on which this estimation is based can be considered as only approximate, the stability constants of the $\beta$ domain of MT with different metal ions have been estimated here for the first time.

\section{Conclusions}

Differential Pulse Polarography, using experimental conditions under which the interaction phenomena between the electrode and the compounds are avoided, is a good technique for monitoring changes of different species in solution and for providing information about complexation properties. It allows one to clearly distinguish between free cations, $\mathrm{Cd}^{2+}$ and $\mathrm{Zn}^{2+}$, and these metal ions complexed with the $\beta$ domain of MT, and consequently allows one to follow the evolution of cadmium and zinc complexes simultaneously. Few analytical techniques can be used for obtaining information, at the same time, of both complexes with similar responses, such as is the case of the reduction of cadmium and zinc at the mercury electrode based on analogous electrochemical mechanisms.

The $\beta$ MT domain is capable of complexing metal ions, cadmium and zinc, at a proportion of three metal ions and one organic molecule when one single ion is complexed with $\beta$ and when both cations are simultaneously added. However the polarographic features are not the same for binary mixtures $\beta+\mathrm{Cd}$ and $\beta+\mathrm{Zn}$ as for the tertiary mixtures $\beta+[\mathrm{Cd}+\mathrm{Zn}]$. In fact two different electrochemical responses of the reduction of $\mathrm{Cd}(\mathrm{II})$ and $\mathrm{Zn}$ (II) have been found and attributed to two different complexes of $\mathrm{Cd}$ and $\mathrm{Zn}$ with the $\beta$ fragment, bearing in mind that it is possible to obtain one of the two responses by varying the relative proportion of cations or by change of $\mathrm{pH}$.

In the case of binary mixtures pure cadmium or zinc complexes are obtained, however, on the contrary, the formation of mixed complexes prevails for tertiary mixtures. When one metal ion, cadmium or zinc, is added to a solution of pure complexes zinc- $\beta$ and cadmium- $\beta$ no displacement of the cation initially bound to the $\beta$ domain is produced, but a reorganisation in the molecules occurs when the metal ion is incorporated by successive additions leading to the formation of a mixed complex. This is displayed by a gradual transformation of the $\mathrm{Cd} \beta$ peak into the $\mathrm{Cd} \beta$ ' when zinc is added to a $\mathrm{Cd}+\beta$ mixture or the appearance and gradual increase of the only $\mathrm{Cd} \beta$ ' peak when cadmium is added to a $\mathrm{Zn}+\beta$ mixture.

Taking into account the values of the apparent stability constants of $\mathrm{Cd}-\beta$ and $\mathrm{Zn}-\beta$ complexes, cadmium should remove the zinc initially bound to the $\beta$ domain as was reported in several papers. However, at $\mathrm{pH} 8$, the $\mathrm{pH}$ at which our experiments were performed and which is higher than that used in most other works, $\log \mathrm{K}_{\mathrm{Zn} \beta} \approx 9$, and the incorporation of cadmium to the complex(es) is produced without the displacement of zinc. The formation of $\mathrm{Zn}-\beta$ complex starts at $\mathrm{pH}>6$ and probably at neutral $\mathrm{pH}$, zinc could more easily be removed by the added cadmium. 
The electrochemical method does not allow one to know if the incorporation of metal ions occurs either with the same kind of co-ordination or if another kind of co-ordination is induced, but allows one to note important changes in the polarographic features for given $\mathrm{Cd} / \mathrm{Zn}$ ratios.

The combination of results obtained using MS techniques from which information of the molecular weight of compounds can be derived, has been very useful for the assignment of different cadmium and zinc electrochemical signals as well as for the confirmation of the hypothesis about the formation of, at least, two complexation forms of cadmium and zinc with the $\beta$ domain of metallothioneins. To our knowledge this paper constitutes the first study on the complexing properties of the $\beta$ MT domain using electroanalytical methods.

\section{Acknowledgement}

The authors gratefully acknowledge Prof. Vašák (University of Zurich) for giving us information about availability of $\alpha$ and $\beta$ MT domains and Dr. Klauser (University of Zurich) for providing us with these carefully synthesised and characterised peptides.

\section{References}

1. Kägi, J.H.R.; Nordberg, M. (eds.) Metallothionein; Basel: Birkhauser, 1979.

2. Kägi, J.H.R.; Kojima, Y. (eds.). Metallothionein II; Basel: Birkhauser, 1987.

3. Stillman, M.J.; Shaw, III C.F.; Suzuki, K.T. (eds.) Metallothioneins, Synthesis, Structure and Properties of Metallothioneins, Phytochelatins and Metal-Thiolate Complexes; New York: VCH, 1992.

4. Riordan, J.F.; Vallée, B.L. (eds.) Methods of Enzymology, Vol. 205. Metallobiochemistry, Part B, Metallothioneins and Related Molecules; London: Academic Press 1991.

5. Suzuki, K.T.; Imura, N.; Kimura, M. (eds.) Metallothionein III, Biological Roles and Medical Implications; Basel: Birkhauser Verlag, 1993.

6. Bordin, G.; Rodríguez, A.R. (eds) Metallothioneins (special issue) Talanta, 1998, 46.

7. Klaassen, C.D. (ed) Metallothionein IV; Basel: Birkhauser Verlag, 1999.

8. Muñoz, A.; Rodríguez, A.R. Electroanalysis 1995, 7, 674-680.
9. Ruiz, C.; Mendieta, J.; Rodríguez, A.R. Anal. Chim. Acta 1995, 305, 285-294.

10. Ruiz, C.; Rodríguez, A.R. Anal. Chim. Acta 1996, 325, 43-51.

11. Ruiz, C.; Rodríguez, A.R. Anal. Chim. Acta 1997, 350, 305317.

12. Nieto, O.; Bordin, G.; Rodríguez, A.R.; Hellemans, G.; DeLey, M. Talanta 1998, 46, 315-324.

13. Nieto, O.; Bordin, G.; Rodríguez, A.R.; Hellemans, G.; DeLey, M. Bioelectrochem. Bioenerg. 1998, 46, 45-54.

14. Harlyk, C.; Nieto, O.; Bordin, G.; Rodríguez, A.R. J. Electroanal. Chem. 1998, 458, 199-208.

15. Dabrio, M.; Rodriguez, A.R. Anal. Chim. Acta 1999, 385, 295306.

16. Dabrio, M.; Rodriguez, A.R. Anal. Chim. Acta 2000, 406, 171181.

17. Mendieta, J.; Chivot, J.; Muñoz, A.; Rodríguez, A.R. Electroanalysis 1995, 7, 663-669.

18. Muñoz, A.; Rodríguez, A.R. Electroanalysis 1995, 7, 670-673.

19. Mendieta, J.; Rodríguez, A.R. Electroanalysis 1996, 8, 473479.

20. Nieto, O.; Rodríguez, A.R. Bioelectrochem. Bioenergetics. 1996, 40, 215-222.

21. Harlyk, C.; Bordin, G.; Nieto, O.; Rodríguez, A.R. Electroanalysis. 1997, 9, 608-613.

22. Harlyk, C.; Bordin, G.; Nieto, O.; Rodríguez, A.R. J. Electroanal. Chem. 1998, 446, 139-150.

23. Harlyk, C.; Bordin, G.; Nieto, O.; Rodríguez, A.R. J. Electroanal. Chem. 1998, 451, 267-272.

24. Nieto, O.; Rodríguez, A.R. Electroanalysis 1999, 11, 175-182.

25. Esteban, M.; Harlyk, C.; Rodríguez, A.R. J. Electroanal. Chem. 1999, 468, 202-212 and references therein.

26. Nielson, K.B.; Winge, D.R. J. Biol. Chem. 1984, 259, 49414946.

27. Okada, Y.; Ohta, N.; Yagyu, M.; Min, K.; Onasaka, S.; Tanaka, K. FEBS Letters 1985, 183, 375-378.

28. Okada, Y.; Ohta, N.; Iguchi, S.; Tsuda, Y.; Sasaki, S.; Kitagawa, T.; Yagyu, M.; Min, K.; Onasaka, S.; Tanaka, K. Chem. Pharm. Bull. 1986, 34, 986-998.

29. Stillman, M.J.; Cai, W.; Zelazowski, A.J. J. Biol. Chem. 1987, 262, 4538-4548.

30. Matsumoto, S.; Nishiyama, Y.; Okada, Y.; Min, K.; Onasaka, S.; Tanaka, K. Chem. Pharm. Bull. 1992, 40, 2701-2706.

31. Li, Y.; Weser, U. Inorg. Chem. 1992, 31, 5526-5533.

32. Capdevilla, M.; Romero, N.; Cols, N.; Atrian, S.; Stillman, M.J.; González-Duarte, P. An. Quim. Int. Ed. 1996, 92, 199201.

33. Bofill, R.; Palacios, O.; Capdevilla, M.; Cols, N.; GonzálezDuarte, P. J. Inorg. Biochem. 1999, 73, 57-65.

34. Klauser, S., Universität Zürich, personal communication.

35. Dabrio, M.; Van Vyncht, G.; Bordin, G.; Rodríguez, submitted for publication in Anal. Chem. 